\title{
Alarm signs and antibiotic prescription in febrile children in primary care:
}

\author{
an observational cohort study
}

\begin{abstract}
Background

Although fever in children is often self-limiting, antibiotics are frequently prescribed for febrile illnesses. GPs may consider treating serious infections by prescribing antibiotics.
\end{abstract}

Aim

To examine whether alarm signs and/or symptoms for serious infections are related to antibiotic prescription in febrile children in primary care.

\section{Design and setting}

Observational cohort study involving five GP outof-hours services.

\section{Method}

Clinical information was registered and manually recoded. Children ( $<16$ years) with fever having a face-to-face contact with a GP were included. Children who were already using antibiotics or referred to secondary care were excluded. The relation between alarm signs and/or symptoms for serious infections and antibiotic prescription was tested using multivariate logistic regression.

\section{Results}

Of the 8676 included patients (median age 2.4 years), antibiotics were prescribed in 3167 contacts (36.5\%). Patient characteristics and alarm signs and/or symptoms positively related to antibiotic prescription were: increasing age lodds ratio [OR] $=1.03 ; 95 \%$ confidence interval $[95 \% \mathrm{Cl}]=1.02$ to 1.05$]$, temperature measured by $\mathrm{GP}(\mathrm{OR}=1.72 ; 95 \% \mathrm{Cl}=1.59$ to 1.86$)$, ill appearance (OR $=3.93 ; 95 \% \mathrm{Cl}=2.85$ to 5.42 ), being inconsolable $\mathrm{OR}=2.27 ; 95 \% \mathrm{Cl}=1.58$ to 3.22 ), shortness of breath $(\mathrm{OR}=2.58 ; 95 \%$ $\mathrm{Cl}=1.88$ to 3.56$)$, duration of fever $(\mathrm{OR}=1.31$; $95 \% \mathrm{Cl}=1.26$ to 1.35 ). Negative associations were found for neurological signs $(\mathrm{OR}=0.45$; $95 \% \mathrm{Cl}=0.27$ to 0.76 ), signs of urinary tract infection (OR $=0.63 ; 95 \% \mathrm{Cl}=0.49$ to 0.82 ), and vomiting and diarrhoea $\mathrm{OR}=0.65 ; 95 \% \mathrm{Cl}=0.57$ to 0.74 ). These variables explained $19 \%$ of the antibiotic prescriptions.

\section{Conclusion}

Antibiotics are often prescribed for febrile children. These data suggest that treatment of a supposed serious bacterial infection is a consideration of GPs. However, the relatively low explained variation indicates that other considerations are also involved.

\section{Keywords}

antibacterial agents; child; child, preschool; family practice; fever; infant; signs and symptoms; primary health care.

\section{INTRODUCTION}

GPs are frequently consulted for fever in children. ${ }^{1}$ Fortunately, since most febrile illnesses are self-limiting, medical intervention is seldom necessary. However, identifying those children with a serious infection (for example, meningitis, sepsis, pneumonia, urinary tract infection [UTI]) is important, since early treatment of such diseases may prevent further complications. Several signs and symptoms are reported to have a predictive value for serious infections in febrile children., ${ }^{2,3}$ However, because most studies on this topic were performed in secondary care, the predictive value of these alarm signs and/or symptoms in primary care still needs to be determined. ${ }^{3}$ Therefore, management of febrile children in primary care remains a challenge. With respect to medical decision-making, children who are clearly ill (for example, with evident meningeal irritation and associated serious risk for infection) are generally immediately referred by the GP to secondary care. More challenging are children who have an alarm sign or symptom, but do not appear to be seriously ill at the time of consultation. In these patients, the GP is uncertain about the presence of a serious infection and

G Elshout, MD, MSc, GP trainee and PhD student; AM Bohnen, MD, PhD, GP and senior researcher, Department of General Practice, Erasmus MC, Rotterdam, the Netherlands;

Y van lerland, MD, MSc, PhD student;

R Oostenbrink, MD, PhD, paediatrician and senior researcher; HA Moll, MD, PhD, paediatrician and professor in general paediatrics, Department of General Paediatrics, Erasmus MC - Sophia Children's Hospital, Rotterdam, the Netherlands. M de Wilde, BSc, scientific programmer,

Department of Medical Informatics, Erasmus MC, Rotterdam, the Netherlands. MY Berger MD, PhD, GP and professor of general practice, Department of General Practice, Erasmus MC, Rotterdam and Department of General Practice. University Groningen, University Medical Center management is less straightforward. It is of interest how GPs cope with these patients. A previous study showed that antibiotics are frequently prescribed in febrile children, but that these prescriptions are not sufficiently explained by the signs and/or symptoms of these children. ${ }^{4}$

Therefore, the present study explores GPs' prescription behaviour for febrile children, with the aim to help diminish unnecessary antibiotic prescriptions in the future. For this, the study assesses whether well-defined alarm signs and symptoms $2,5,6$ are related to antibiotic prescription in febrile children presenting at GP cooperatives' out-of-hours services.

\section{METHOD}

\section{Study design}

This cohort study used data of face-to-face patient contacts (physical consultations and home visits) of children aged $\leq 16$ years that took place at GP cooperative out-ofhours services of Rotterdam-Rijnmond between March 2008 and February 2009 ( $n=28$ 234). This district has five GP cooperatives (totalling $\geq 250$ GP practices) providing out-of-hours care for almost 1 million inhabitants living in this urban, multi-ethnic area. All five GP cooperatives

Groningen, the Netherlands.

\section{Address for correspondence}

Marjolein Berger, University Groningen, University Medical Center Groningen, Department of General Practice, PO Box 196, 9700 AD Groningen, the Netherlands.

E-mail: m.y.bergeraumcg.nl

Submitted: 27 September 2013; Editor's response: 29 November 2012; final acceptance: 5 February 2013

CBritish Journal of General Practice

This is the full-length article (published online $1 \mathrm{Jul}$ 2013) of an abridged version published in print. Cite this article as: Br J Gen Pract 2013; DOI: 10.3399/bjgp13X669158 


\section{How this fits in}

Although fever in children is often selflimiting, antibiotics are still frequently prescribed. Medical considerations for prescribing antibiotics are treatment of serious infections, or to reduce the duration of the illness. It is shown that alarm signs and symptoms explain only a small part of frequent antibiotic prescription. Therefore, considerations that are not medically based may play a considerable role in the GP's decision to prescribe antibiotics.

used the same information system l'Call Manager', Labelsoft, Zoetermeer, the Netherlands) to register patient data. In this system, information from telephone triage, patient history, physical examination, diagnostic intervention, (working) diagnosis, and treatment or referral is documented (by GPs and physician assistants) as written text lines in a semi-structured data sheet.

\section{Out-of-hours healthcare system}

In the Netherlands, and also in the UK, Scandinavia, and Australia, out-of-hours primary care $(5 \mathrm{pm}$ to 8 am daily and the entire weekend) is organised in large-scale cooperatives. ${ }^{7-11}$ In the Netherlands, GPs rotate shifts at the GP cooperatives to cover the out-of-hours primary care. Referral to secondary care is required for about $5-10 \%$ of all primary care consultations, 7,12 which is similar to the referral rates in the UK, US, and Canada. ${ }^{13,14}$

\section{Study population}

Children aged $\leq 16$ years with: (1) fever reported as the reason for contact; (2) fever within 24 hours prior to contact; or (3) a temperature $\geq 38^{\circ} \mathrm{C}$ measured at the GP cooperative were eligible for inclusion. Children could contribute more than one contact to the total of patient contacts if that contact was not related to the same illness episode, that is, it occurred more than 7 days after the initial contact. Exclusion criteria were: referral to secondary care, telephone consultations (in the Netherlands antibiotics are never prescribed by telephone), patients consulting the GP cooperative and already using antibiotics, and repeated contacts within 7 days of the initial presentation concerning the same febrile illness.

\section{Extraction of relevant clinical signs}

Signs and symptoms that are indicative of a potential serious infection ('red flags') were derived from one systematic review, ${ }^{2}$ and two published guidelines on management of febrile children. 5,6 The study included signs that: (1) had a high predictive value (positive likelihood ratio $>5.0$ or negative likelihood ratio <0.2); (2) were mentioned in at least two of the three data sources; (3) did not represent a diagnosis; and (4) were not prone to high interobserver variability (for example, auscultatory sounds)..$^{15}$ Selected, closely related signs were grouped into a total of 18 alarm signs of serious febrile illness (Appendix 1). Using a data-entry computer program (Embarcadero Delphi XE, Version 15.0), all eligible contacts were recoded according to whether the grouped alarm signs were 'present', 'absent', or 'not mentioned' in the patient record. In addition, 'referral to secondary care', or 'antibiotic prescription' by the GP was recoded as 'yes' or 'no'.

\section{Missing data}

Since the alarm signs and/or symptoms were obtained from routinely collected, semi-structured data, missing values occurred for each variable (that is, not mentioned in the record). Therefore, a consensus meeting was held, with one GP, two paediatricians, one GP trainee, and one trainee paediatrician, to discuss this. Based on the prevalence of serious illnesses in the primary care setting, clinical experience, and common knowledge, for the purpose of this study missing values were handled in two ways: (1) the sign or symptom was believed to be so relevant that, if present, the physician would document it. Consequently, all missing values were interpreted as being absent lill appearance, $\mathrm{ABC}$ [airways, breathing, circulation] instability, unconsciousness, drowsiness, being inconsolable, cyanosis, shortness of breath, meningeal irritation, neurological signs; that is, typical and atypical febrile convulsions, focal neurological signs, vomiting and diarrhoea, dehydration, petechial rash, extremity problems); (2) for the remaining signs and symptoms Iparental concern, abnormal circulation, signs of $\mathrm{UTI}$, temperature $\geq 40^{\circ} \mathrm{C}$, and duration of fever), it was decided that the above statements were not applicable. For these variables, multiple imputation was performed if missing data were $<70 \%{ }^{16}$ Signs and symptoms with $\geq 70 \%$ missing data were excluded from the analyses.

\section{Statistical analyses}

In the original dataset, patient characteristics and frequency of antibiotic prescription were analysed using descriptive 


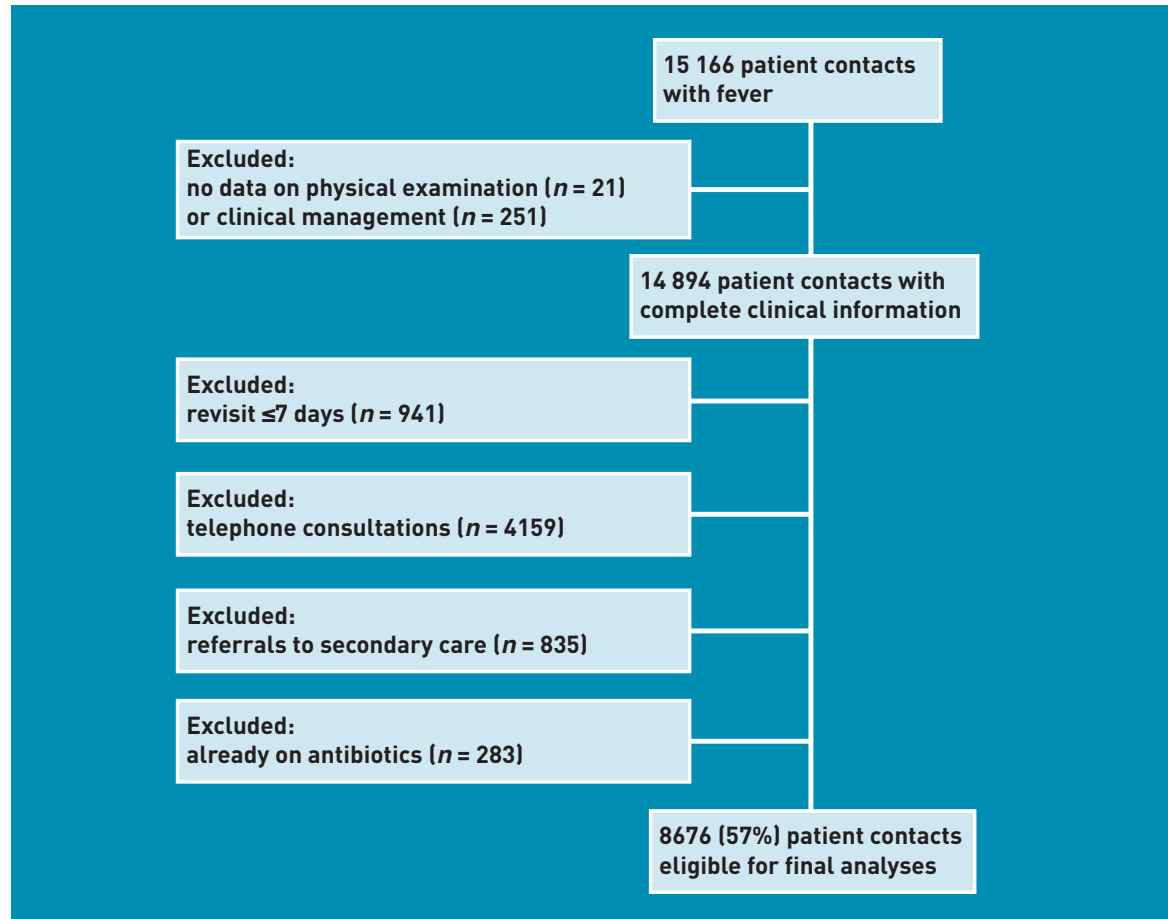

Figure 1 Selection of eligible patient contacts.

\section{Table 1. Characteristics of the study population $(n=8676)$}

\section{Characteristics}

\begin{tabular}{lc}
\hline Age in years, median (IQR) & $2.4(1.1$ to 4.7$)$ \\
\hline Male sex, $n(\%)$ & 4601 (53) \\
\hline $\begin{array}{l}\text { Rectal temperature in }{ }^{\circ} \mathrm{C}, \\
\text { median (IQR) }\end{array}$ & $38.4(37.7$ to 39.1) \\
\hline $\begin{array}{l}\text { Antibiotic prescription, } \\
n(\%)\end{array}$ & $3167(36.5)$ \\
\hline $\begin{array}{l}\text { Duration of fever in days } \\
(n=6933), \text { median (IQR) }\end{array}$ & $2.0(0$ to 3) \\
\hline $\begin{array}{l}\text { IQR = interquartile range. } \\
\end{array}$
\end{tabular}

statistics. Missing data were imputed using MICE in R-2.11.1 for Windows. Backward stepwise logistic regression of variables was performed manually, using Akaike information criterion of $P>0.157$ for dropping variables. ${ }^{17}$ If multicollinearity was present, the variable under investigation that least contributed to the model was dropped. The proportion of variability in the dataset that is accounted for by the final statistical model was determined using Nagelkerke $R^{2}$. Data were analysed using PASW (version 17.0.2 for Windows).

\section{RESULTS}

\section{Description of the population}

A total of 15166 patient contacts at the five GP cooperatives concerned fever. Of 272 patient contacts, no data on physical examination or clinical management were available, and these were subsequently excluded. After applying the exclusion criteria, 8676 patient contacts were available for the present analysis (Figure 1). In total, 3167 of the contacts (36.5\%) were prescribed antibiotics at the GP cooperative. Additional baseline characteristics of these patients are presented in Table 1. Figure 2 shows the distribution of antibiotic prescription by age, rectal temperature,

\section{Multivariate logistic regression}

Table 2 presents the alarm signs and/ or symptoms that were tested for their and duration of fever. independent association with antibiotic prescription. Patient characteristics, and alarm signs and/or symptoms positively related to antibiotic prescription were: increasing age (years), temperature measured by the GP, ill appearance, being inconsolable, shortness of breath, and duration of fever (Table 3). A significant negative association was found for neurological signs, signs of UTI, and vomiting and diarrhoea. The median Nagelkerke $R^{2}$ of this final multivariate model was 0.19 (range $=0.18$ to 0.20 ).

\section{DISCUSSION}

\section{Summary}

This large study, evaluating 8676 face-toface contacts of febrile children presenting at five GP cooperatives, shows that antibiotics were prescribed in $36.5 \%$ of the patient contacts. Multivariate analysis revealed that several alarm signs and/ or symptoms were significantly related to antibiotic prescription, suggesting that treating a potentially serious bacterial infection is a consideration of the GP. However, the relatively low explained variation $\left(R^{2}=0.19\right)$ shows that other considerations, not included in the analysis, also made a substantial contribution.

\section{Strengths and limitations}

A major strength of the study is the large number of patient records. This minimises the probability that the results are based on chance, and lack of power plays no role in the non-significant related variables.

The study did not look for any relation between (working) diagnosis and antibiotic prescription. This is based on the fact that GPs make diagnostic transfers to diagnoses that justify their antibiotic prescription. ${ }^{18}$ Therefore, these diagnoses are ultimately related to the signs and/or symptoms of the presenting febrile child. Therefore, investigating the relation between alarm signs and/or symptoms and antibiotic prescription seems more appropriate.

The GPs did not record the signs and symptoms in a fully structured way. Therefore, when a characteristic was not recorded, it is possible that the variable was absent and that the GP did not write it down, or that the GP did not look for that particular sign or symptom. This problem was discussed in a consensus meeting including specialists in family medicine and paediatrics. It seems legitimate to consider some signs (for example, unconsciousness) as being absent when the GP did not report this, since if that sign had been present the GP would always notice and record 
Figure 2. Distribution of percentage antibiotic prescription by age group, rectal temperature, and duration of fever.

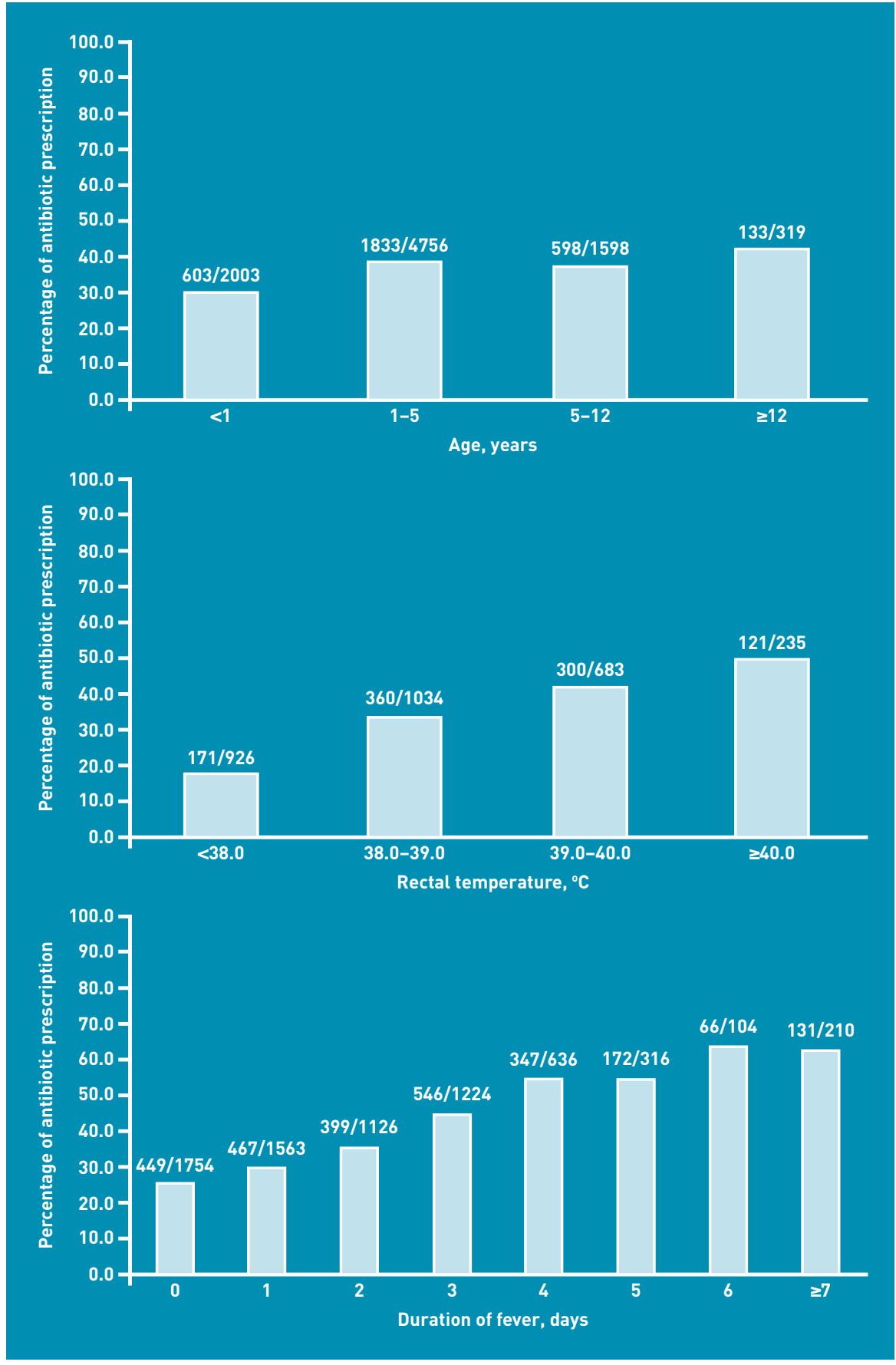

it. This is especially so since the Dutch guideline specifically advises to look for the various alarm signs and/or symptoms when assessing a febrile child. ${ }^{5}$

\section{Comparison with existing literature}

In the present study, the amount of prescribed antibiotics (36.5\%) is similar to the $36.3 \%$ prescribed in a previous study. Although this latter study was performed in younger children, overall it is similar to the present one with regard to the setting, study population, and clinical guidelines used.
When selecting the same age category in the present study, $35.0 \%$ of children aged 3 months to 6 years were prescribed antibiotics, that is, a rate very similar to the earlier report.

Surprisingly, increasing age was prescription. This was unexpected since younger children are more at risk of a serious infection, and therefore more cautious management (that is, more antibiotic prescriptions) could be expected. However, since febrile illnesses in young significantly related to antibiotic 
Table 2. Alarm signs and symptoms and prescribed antibiotics

\begin{tabular}{|c|c|c|c|}
\hline \multirow{2}{*}{$\begin{array}{l}\text { Signs and symptoms } \\
\text { included in the analysis }\end{array}$} & \multicolumn{3}{|c|}{ Percentage of antibiotic prescription $(n)^{\mathrm{a}}$} \\
\hline & Sign present & Sign absent & Missing, $\%$ \\
\hline Temperature (at GPC) & NA & NA & 66.8 \\
\hline Abnormal circulation & $31.8(27 / 85)$ & $31.0(657 / 2121)$ & 25.4 \\
\hline Signs of urinary tract infection & $24.6(99 / 403)$ & $36.0(1112 / 3093)$ & 40.3 \\
\hline Parental concern ${ }^{b}$ & $27.8(416 / 1497)$ & $25.0(1 / 4)$ & 82.7 \\
\hline Temperature $\geq 40^{\circ} \mathrm{C}^{b}$ & $40.1(878 / 2190)$ & $35.2(1889 / 5371)$ & 87.1 \\
\hline Duration of fever & NA & NA & 21.1 \\
\hline Ill appearance & $76.3(203 / 266)$ & $35.2(2964 / 8410)$ & \\
\hline Being inconsolable & $54.1(119 / 202)$ & $36.0(3048 / 8474)$ & \\
\hline Cyanosis & $66.7(14 / 21)$ & $36.4(3153 / 8655)$ & \\
\hline Shortness of breath & $57.6(144 / 250)$ & $35.9(3023 / 8426)$ & \\
\hline Meningeal irritation & $50.0(3 / 6)$ & $36.5(3164 / 8670)$ & \\
\hline Neurological signs & $20.4(21 / 103)$ & $36.7(3146 / 8573)$ & \\
\hline Vomiting and diarrhoea & $29.4(517 / 1760)$ & $38.3(2650 / 6916)$ & \\
\hline Dehydration & $29.4(5 / 17)$ & $36.5(3162 / 8659)$ & \\
\hline Extremity problems & $37.5(3 / 8)$ & $36.5(3164 / 8668)$ & \\
\hline Petechial rash & $36.8(7 / 19)$ & $36.5(3160 / 8657)$ & \\
\hline Drowsiness $^{c}$ & $0.0(0 / 3)$ & $36.5(3167 / 8676)$ & \\
\hline ABC instabilityc & NA & $36.5(3167 / 8676)$ & \\
\hline Unconsciousness $^{c}$ & NA & $36.5(3167 / 8676)$ & \\
\hline $\begin{array}{l}\text { 'Number of patients with antibiotics, } \\
\text { to missing values }>70 \% \text {. 'Not includ } \\
\text { and positive antibiotic prescription). } \\
\text { applicable. }\end{array}$ & $\begin{array}{l}\text { total number of pati } \\
\text { led in the analyses, } 0 \\
A B C=\text { airways, breat }\end{array}$ & $\begin{array}{l}\text { group. }{ }^{b} \text { Not included } \\
\text { o events lpositive ala } \\
\text { ulation. } G P C=G P c c\end{array}$ & $\begin{array}{l}\text { yses, owing } \\
\text { ymptoms } \\
N A \text { not }\end{array}$ \\
\hline
\end{tabular}

\section{Table 3. Final multivariate analysis of alarm signs and symptoms that were significantly related to antibiotic prescription}

\begin{tabular}{|c|c|}
\hline Variables & OR (95\% Cl) \\
\hline Age, years & 1.03 (1.02 to 1.05$)$ \\
\hline $\begin{array}{l}\text { Temperature } \\
\text { Imeasured by the } \mathrm{GP} \text { in }{ }^{\circ} \mathrm{C}\end{array}$ & $1.72(1.59$ to 1.86$)$ \\
\hline IIl appearance & 3.93 (2.85 to 5.42 ) \\
\hline Being inconsolable & 2.27 (1.58 to 3.22 ) \\
\hline Shortness of breath & 2.58 (1.88 to 3.56 ) \\
\hline Neurological signs ${ }^{a}$ & 0.45 (0.27 to 0.76$)$ \\
\hline Vomiting and diarrhoea $^{a}$ & 0.65 (0.57 to 0.74 ) \\
\hline $\begin{array}{l}\text { Signs of urinary tract } \\
\text { infection }\end{array}$ & 0.63 (0.49 to 0.82 ) \\
\hline Duration of fever, days & 1.31 (1.26 to 1.35 \\
\hline
\end{tabular}

children can deteriorate quickly, the GP may take even more precautions than simply prescribing antibiotics. For example, in this earlier study, ${ }_{1}^{4}$ children referred to secondary care were significantly younger than those included in the analyses: median age 1.6 years (interquartile range $[I Q R]=0.6$ to 3.6 versus 2.4 years, IQR $=1.1$ to 4.7 ) (Mann-Whitney U test <0.01). Perhaps the consideration of prescription of antibiotics is less important in younger children than the consideration of whether or not to immediately refer them to secondary care. A similar explanation may apply to the negative associations found between antibiotic prescription and neurological signs and vomiting and/or diarrhoea. Children with these signs are also more often referred to secondary care ldata not shown). Another explanation for the findings related to children with vomiting and/or diarrhoea is that it is not reasonable to administer antibiotics in children with these alarm signs, since the risk of bacterial infection is considered to be low. ${ }^{19}$

Compared with other European countries, GPs in the Netherlands have one of the lowest overall rates of antibiotic prescription. ${ }^{20,21}$ Nevertheless, in the present study more than one out of three children were prescribed antibiotics. Although other studies also reported antibiotic prescription rates, they were performed in different study populations (for example, only children with acute otitis media, not solely febrile children), ${ }^{21-24}$ making comparison with the present results difficult.

The GP cooperative out-of-hours setting was chosen because a high number of consultations concerning fever was expected. One in five consultations at a GP cooperative out-of-hours service concerns children laged 3 months to 5 years), and in almost half of these children, fever is the reason for encounter lunpublished data). Patient characteristics like sociodemographic status are expected to be similar to those of children seen during regular hours, since the region for the outof-hours care, and the regular hours care is the same. However, at the GP cooperative, triage is performed to select the children that need immediate assessment, and those that can wait until regular hours. Therefore, the children in the present study might be more seriously ill compared with those seen during regular hours and, therefore, may have had more alarm signs and/or symptoms and have been more eligible for antibiotic treatment. However, if this was the case, the explained variation in antibiotic prescription should be even higher, since alarm signs and/or symptoms are thought to be indicative of the severity of disease.

Furthermore, in the Netherlands, GPs are not familiar with the patients assessed at the out-of-hours service, and followup of these patients is performed by another physician. This may make it more difficult to provide adequate safety netting. Ultimately, this may lead to more defensive management and to more antibiotic prescription.

The present study shows that only a small proportion of the antibiotic prescriptions is explained by the related alarm signs and symptoms. This is not surprising, since other clinical features may also contribute to considering whether to prescribe antibiotics (for example, otorrhoea, bulging tympanic membrane). ${ }^{25-28}$ Unfortunately, information on these clinical features was not available in this study, and could therefore not be included in the analyses. The explained variation of antibiotic prescriptions might have been higher, if these variables could have been added. This assumption was confirmed by the 
previous study in a similar setting, in which it was shown that variables like signs of throat infection or earache are also related to antibiotic prescription. ${ }^{4}$ In that study, multivariate analysis explained $26 \%$ of the proportion of variation. Hypothetically, in the most positive perspective, $45 \%$ of the variation in antibiotic prescription is explained by the two studies; however, this is not actually the case, since there is some overlap in the signs and symptoms (for example, ill appearance). This indicates that in $\geq 55 \%$ of the prescribed antibiotics, other (unknown) factors contribute to the GP's decision to prescribe antibiotics. Earlier studies found that non-medically based considerations may also contribute to the GP's decision to prescribe antibiotics, for example, assuming that the patient or the parents expect antibiotics. ${ }^{29-31}$ However, these assumptions are not always valid, ${ }^{32-34}$ and GPs may need to reconsider their management of febrile children.

Bacterial resistance to antibiotics is a growing problem. $^{20}$ Since overuse of antibiotics contributes to this problem, prevention of unnecessary prescription is important. ${ }^{20,35}$ Since $\geq 50 \%$ of the prescribed antibiotics do not appear to be based on medical considerations, strategies to diminish antibiotic prescription should focus on this aspect. Cals et al reported that point-of-care testing of $\mathrm{C}$-reactive protein (CRP) and training in communication skills significantly reduced antibiotic prescribing for lower respiratory tract infection, without compromising patients' recovery and satisfaction with care. ${ }^{36}$ However, the role of CRP in febrile children in primary care needs further elucidation. ${ }^{37}$ It may be useful to investigate whether a negative CRP can reassure both patients and GPs in the decision-making process, and thereby diminish antibiotic prescription.

In the present study, ill appearance, being inconsolable, shortness of breath, increasing temperature, and longer duration of fever were significantly and positively related to antibiotic prescription. All of these signs and/or symptoms are suggested to be related to serious infections, mostly in secondary care settings. ${ }^{2}$ Prescribing antibiotics in these children suggests that GPs may be concerned about the (future) course of the febrile disease, and therefore want to treat or prevent potential complications of a serious bacterial infection. However, although oral antibiotics are helpful in some serious bacterial infections like pneumonia, UTI, or acute tonsillitis (prevention of peritonsillar abscess), ${ }^{27-28,38,39}$ they are not useful in the initial treatment of rare serious bacterial infections like meningitis or sepsis. In addition, antibiotics frequently cause side effects. Therefore, the disadvantages of antibiotics should be weighed against their limited benefits in treating and preventing serious bacterial infections.

Signs of UTI were significantly related to less antibiotic prescription; this is surprising because a UTI is a clear indication for antibiotics. ${ }^{39}$ However, this result can be explained by the fact that this variable is composed of several signs, including pollakiuria, dysuria, and abdominal pain without diarrhoea or other focus of the fever (Appendix 1). This may explain the lack of a significant relation between signs of UTI and antibiotic prescription. Another, more disturbing, explanation may be that GPs do not endorse the signs and/or symptoms of a possible UTI. Recognition and treatment of UTIs in children is important since they can cause transient or permanent kidney damage. ${ }^{40,41}$

\section{Implications for research and practice}

In conclusion, the present study revealed a substantial amount of antibiotic prescriptions in febrile children who presented to the five GP cooperative out-ofhours services. Only a small proportion of antibiotic prescribing is explained by alarm signs and/or symptoms; this implies that other, non-medically based considerations may also play a role in the GP's decision to prescribe antibiotics. Future research should focus on the unexplained antibiotic prescriptions, and the value of CRP when assessing febrile children in primary care. ${ }^{37}$ This can then be used to provide more adequate management (for example, more efficient safety netting, and fewer prescribed antibiotics) of febrile children in primary care.

\section{Acknowledgements}

We thank T Krecinic, Z Gocmen, M Hofhuis, and $M$ Rotsteeg for their contribution to the data management of this study.

\section{Discuss this article}

Contribute and read comments about this article on the Discussion Forum: http://www.rcgp.org.uk/bjgp-discuss 


\section{REFERENCES}

1. Bruiinzeels MA, Foets M, van der Wouden JC, et al. Everyday symptoms in childhood: occurrence and general practitioner consultation rates. $\mathrm{Br} J \mathrm{Gen}$ Pract 1998; 48(426): 880-884.

2. Van den Bruel A, Haj-Hassan T, Thompson M, et al. Diagnostic value of clinical features at presentation to identify serious infection in children in developed countries: a systematic review. Lancet 2010; 375(9717): 834-845.

3. Thompson M, Van den Bruel A, Verbakel J, et al. Systematic review and validation of prediction rules for identifying children with serious infections in emergency departments and urgent-access primary care. Health Technol Assess 2012; 16(15): 1-100.

4. Elshout G, Kool M, Van der Wouden JC, et al. Antibiotic prescription in febrile children: a cohort study during out-of-hours primary care. J Am Board Fam Med 2012; 25(6): 810-818

5. Berger MY, Boomsma LJ, Albeda FW, et al. The standard of the Dutch College of General Practitioners on children with fever. Huisarts Wet 2008; 51(6): 287-296.

6. Richardson M, Lakhanpaul M. Assessment and initial management of feverish illness in children younger than 5 years: summary of NICE guidance. BMJ 2007; 334(7604): 1163-1164.

7. Giesen P, Smits M, Huibers L, et al. Quality of after-hours primary care in the Netherlands: a narrative review. Ann Intern Med 2011; 155(2): 108-113.

8. Zwakhals SLN, Vugt CJ, Sterren EGS. Locations of general practitioner cooperatives and emergency departments in the Netherlands 2010 [Locaties huisartsenposten en spoedeisende hulpen 2010]. Bilthoven, Dutch National Atlas of Public Health, National Institute for Public Health and the Environment, Ministry of Health, Welfare and Sport, 2010.

9. Hallam L. Primary medical care outside normal working hours: review of published work. BMJ 1994; 308(6923): 249-253.

10. Hansen BL, Munck A. Out-of-hours service in Denmark: the effect of a structural change. Br J Gen Pract 1998; 48(433): 1497-1499.

11. Huibers L, Giesen $P$, Wensing M, Grol R. Out-of-hours care in western countries: assessment of different organizational models. BMC Health Serv Res 2009; 9: 105.

12. van lerland $Y$, van Veen $M$, Huibers $L$, et al. Validity of telephone and physical triage in emergency care: the Netherlands Triage System. Fam Pract 2011; 28(3): 334-341.

13. Forrest CB. Primary care in the United States: primary care gatekeeping and referrals: effective filter or failed experiment? BMJ 2003; 326(7391): 692-695.

14. Patel S, Dubinsky I. Outcomes of referrals to the ED by family physicians. Am J Emerg Med 2002; 20(3): 144-150.

15. Muris JWM. Lung auscultation in general practice. A literature survey. Huisarts Wet 1990; 33(7): 258-262.

16. Donders AR, van der Heijden GJ, Stijnen T, Moons KG. Review: a gentle introduction to imputation of missing values. J Clin Epidemiol 2006; 59(10): 1087-1091.

17. Ambler G, Brady AR, Royston P. Simplifying a prognostic model: a simulation study based on clinical data. Stat Med 2002; 21(24): 3803-3822.

18. Thompson PL, Spyridis N, Sharland M, et al. Changes in clinical indications for community antibiotic prescribing for children in the UK from 1996 to 2006: will the new NICE prescribing guidance on upper respiratory tract infections just be ignored? Arch Dis Child 2009; 94(5): 337-340.

19. de Wit MA, Koopmans MP, Kortbeek LM, et al. Etiology of gastroenteritis in sentinel general practices in the netherlands. Clin Infect Dis 2001; 33(3): 280288.

20. Goossens H, Ferech M, Vander Stichele R, Elseviers M. Outpatient antibiotic use in Europe and association with resistance: a cross-national database study. Lancet 2005; 365(9459): 579-587.

21. Rossignoli A, Clavenna A, Bonati M. Antibiotic prescription and prevalence rate in the outpatient paediatric population: analysis of surveys published during 2000-2005. Eur J Clin Pharmacol 2007; 63(12): 1099-1106.
22. Lusini G, Lapi F, Sara B, et al. Antibiotic prescribing in paediatric populations: a comparison between Viareggio, Italy and Funen, Denmark. Eur J Public Health 2009; 19(4): 434-438

23. Plasschaert Al, Rovers MM, Schilder AG, et al. Trends in doctor consultations, antibiotic prescription, and specialist referrals for otitis media in children: 19952003. Pediatrics 2006; 117(6): 1879-1886.

24. Finkelstein JA, Metlay JP, Davis RL, et al. Antimicrobial use in defined populations of infants and young children. Arch Pediatr Adolesc Med 2000; 154(4): $395-400$

25. Damoiseaux RAMJ, Van Balen FAM, Leenheer WAM, Kolnaar BGM. The standard for acute otitis media in children of the Dutch College of General Practitioners: Second revision. Huisarts Wet 2006; 49(12): 615-621.

26. De Sutter A, Burgers JS, De Bock GH, et al. Standard for rhinosinusitis of the Dutch College of General Practitioners - second revision. Huisarts Wet 2005; 48(12): 615-624

27. Verheij TIM, Salome PL, Bindels PI, et al. Standard for acute cough of the Dutch Association for General Practitioners. Huisarts Wet 2003; 46(9): 496-506.

28. Zwart S, Dagnelie CF, Van Staaij BK, et al. Standard on acute sore throat of the Dutch College of General Practitioners - second revision. Huisarts Wet 2007; 50(2): 59-68.

29. Akkerman AE, Kuyvenhoven MM, van der Wouden JC, Verheij TJ. Determinants of antibiotic overprescribing in respiratory tract infections in general practice. $J$ Antimicrob Chemother 2005; 56(5): 930-936.

30. Akkerman AE, Kuyvenhoven MM, van der Wouden JC, Verheij TJ. Analysis of under- and overprescribing of antibiotics in acute otitis media in general practice. J Antimicrob Chemother 2005; 56(3): 569-574.

31. Welschen I, Kuyvenhoven M, Hoes A, Verheij T. Antibiotics for acute respiratory tract symptoms: patients' expectations, GPs' management and patient satisfaction. Fam Pract 2004; 21(3): 234-237.

32. Ong S, Nakase J, Moran GJ, et al. Antibiotic use for emergency department patients with upper respiratory infections: prescribing practices, patient expectations, and patient satisfaction. Ann Emerg Med 2007; 50(3): 213-220.

33. Ring A, Dowrick C, Humphris G, Salmon P. Do patients with unexplained physical symptoms pressurise general practitioners for somatic treatment? A qualitative study. BMJ 2004; 328(7447): 1057.

34. Salmon P, Dowrick CF, Ring A, Humphris GM. Voiced but unheard agendas: qualitative analysis of the psychosocial cues that patients with unexplained symptoms present to general practitioners. Br J Gen Pract 2004; 54(500): 171-176.

35. Jacobs MR, Dagan R. Antimicrobial resistance among pediatric respiratory tract infections: clinical challenges. Semin Pediatr Infect Dis 2004; 15(1): 5-20.

36. Cals JW, Butler CC, Hopstaken RM, et al. Effect of point of care testing for C reactive protein and training in communication skills on antibiotic use in lower respiratory tract infections: cluster randomised trial. BMJ 2009; 338: b1374.

37. Van den Bruel A, Thompson MJ, Haj-Hassan T, et al. Diagnostic value of laboratory tests in identifying serious infections in febrile children: systematic review. BMJ 2011; 342: d3082.

38. Del Mar CB, Glasziou PP, Spinks AB. Antibiotics for sore throat. Cochrane Database Syst Rev 2006; (4): CD000023.

39. Van Haaren KAM, Visser HS, Van Vliet S, et al. Standard on urinary tract infections of the Dutch College of General Practitioners. Huisarts Wet 2005; 48(7): $341-352$.

40. Coulthard MG, Lambert HJ, Keir MJ. Occurrence of renal scars in children after their first referral for urinary tract infection. BMJ 1997; 315(7113): 918-919.

41. Craig JC, Irwig LM, Knight JF, et al. Symptomatic urinary tract infection in preschool Australian children. J Paediatr Child Health 1998; 34(2): 154-159. 


\begin{tabular}{|c|c|}
\hline Composed alarm signs and symptoms & Total selection of alarm signs and symptoms \\
\hline Parental concern & Parental concern \\
\hline Ill appearance & $\begin{array}{l}\text { Clinician's instinct something is wrong } \\
\text { Clinically ill appearance }\end{array}$ \\
\hline $\mathrm{ABC}$-instability & ABCD-instability \\
\hline Unconsciousness & Unconsciousness \\
\hline Drowsiness & $\begin{array}{l}\text { Child is drowsy } \\
\text { Somnolence } \\
\text { Reactivity/functional status (decreased) } \\
\text { Hypotonia }\end{array}$ \\
\hline Inconsolable & $\begin{array}{l}\text { Child is inconsolable } \\
\text { Irritability } \\
\text { Changed crying pattern } \\
\text { Child is moaning }\end{array}$ \\
\hline Abnormal circulation & $\begin{array}{l}\text { Abnormal skin colour (pale, mottled, ashen) } \\
\text { Capillary refill time }>2 \text { seconds } \\
\text { Tachycardia }\end{array}$ \\
\hline Cyanosis & $\begin{array}{l}\text { Cyanosis } \\
\text { Oxygen saturation }<95 \%\end{array}$ \\
\hline Shortness of breath & $\begin{array}{l}\text { Shortness of breath } \\
\text { Nasal flaring } \\
\text { Rapid breathing } \\
\text { Changed breathing pattern }\end{array}$ \\
\hline Meningeal irritation & $\begin{array}{l}\text { Meningeal irritation } \\
\text { Neck stiffness } \\
\text { Bulging fontanelle }\end{array}$ \\
\hline Neurological signs & $\begin{array}{l}\text { Focal neurological signs } \\
\text { Paresis/paralysis } \\
\text { Seizures/fits }\end{array}$ \\
\hline Vomiting and diarrhoea & $\begin{array}{l}\text { Vomiting ( }>2 \times \text { in disease period) } \\
\text { Diarrhoea ( }>2 x \text { in disease period) }\end{array}$ \\
\hline Dehydration & $\begin{array}{l}\text { Dry mucous membranes } \\
\text { Sunken eyes } \\
\text { Decreased skin elasticity } \\
\text { Reduced urine output } \\
\text { Hypotension (APLs) } \\
\text { Poor feeding }\end{array}$ \\
\hline Extremity problems & $\begin{array}{l}\text { Swelling of limb or joint } \\
\text { Non-weight-bearing limb } \\
\text { Not using an extremity }\end{array}$ \\
\hline Signs of urinary tract infection & $\begin{array}{l}\text { Pollakiuri } \\
\text { Dysuria } \\
\text { Abdominal pain (without other focus for fever) }\end{array}$ \\
\hline Petechial rash & $\begin{array}{l}\text { Petechial rash } \\
\text { Purpura }\end{array}$ \\
\hline Temperature $\geq 40^{\circ} \mathrm{C}$ & $\begin{array}{l}\text { Measured at home or at a GPs' cooperative } \\
\text { out-of-hours service }\end{array}$ \\
\hline Duration of fever & Duration of fever in days at time of consultation \\
\hline
\end{tabular}

